\title{
Agricultura tóxica y pueblos fumigados en Argentina
}

Medardo Ávila-Vazquez

Coordinador de la Red Universitaria de Ambiente y Salud de Argentina. Médicos de Pueblos Fumigados.

Docente de la Facultad de Medicina.

Universidad Nacional de Córdoba.

\section{Presentación}

En los últimos veinte años, la frontera agrícola se ha expandido casi en un $50 \%$, avanzando sobre regiones destinadas a otras producciones, sobre territorios con agriculturas familiares $\mathrm{y}$, masivamente, sobre bosques.

La tonelada de soja, que cotizaba a U\$S 160 en 2001, en julio de 2012 valía U\$S 600; el rendimiento promedio es de 3 a 4 toneladas por hectárea; los costos de producción son de 200 a U\$S 250 por hectárea: la rentabilidad es descomunal. De un total de 300000 productores rurales existentes en todo el país, 80000 se dedican a esta agricultura transgénica y química, pero de ellos sólo 20000 concentran el $70 \%$ de la producción y son básicamente sociedades anónimas y pooles de siembra que producen en campos alquilados, intrusando territorios de pueblos originarios o de campesinos ancestrales (Lapolla, 2008).

La agricultura dominante se sostiene sobre un modelo de monocultivo agroindustrial que utiliza un paquete tecnológico que incluye siembra directa, semillas transgénicas y aplicación de agrotóxicos. En ese marco, como consecuencia de la inviabilidad natural del monocultivo y para poder sostener la producción, se aplican cantidades cada vez mayores de agroquímicos en un territorio donde conviven con los cultivos transgénicos más de 12 millones de personas.

Es preciso reconocer que los productos que se emplean allí son todos venenos. Los herbicidas, como el glifosato, 2.4D o atrazina, están destinados a matar plantas; y los más utilizados para matar insectos son endosulfán, clorpirifós, dimetoato, cipermetrina, imidacloprid, etc. Todos tienen efectos deletéreos sobre la salud humana y contaminan el ambiente.
Universidad y salud /

Perspectivas

\section{Resumen}

Hace 18 años se instauró en Argentina un sistema de producción agraria cimentada en el uso de semillas transgénicas y aplicación masiva de agrotóxicos o plaguicidas. Desde entonces los vecinos de los pueblos fumigados protestan porque se ven afectados en su salud y los médicos de esos pueblos corroboran un cambio del patrón de enfermedad y de muerte en estas comunidades. Trastornos endócrinos e inmunológicos, neumopatías crónicas, abortos espontáneos en mujeres sanas, malformaciones congénitas y cáncer son las enfermedades que se reiteran en poblaciones expuestas a dosis crecientes de agrotóxicos. Estudios epidemiológicos e investigaciones de laboratorios confirman el vínculo entre pesticidas, como glifosato, y daños en la salud. A pesar de las protestas y denuncias, aumenta el consumo de agrotóxicos y las empresas biotecnológicas preparan nuevas semillas que auguran un futuro cercano de mayor toxicidad y contaminación, lo cual pone en peligro la salud colectiva.

\section{Palabras clave}

- plaguicidas

- salud colectiva

- cáncer

- glifosato

- semillas transgénicas
La utilización de estos agrotóxicos aumenta exponencialmente desde el año 1990 hasta alcanzar 318 millones de litros/kilos en el 2013. En la misma hectárea donde se usaban 2 ó 3 litros de glifosato por año, hoy se usan 8 ó 12 litros y se le agrega 1,5 litros de 2.4D por año. En Santiago del Estero, Salta y Chaco (noroeste argentino) se utilizan hasta 20 litros por hectárea por año de Round Up (REDUAS, 2013).

Para cultivar 100 hectárea de soja transgénica se requieren 14 días de trabajo de un solo operario (Lapolla, 2008). De esas jornadas, un día sembrará, otro día cosechará las 100 hectáreas y los otros 12 días aplicará venenos sobre el mismo predio. Esa es toda la actividad productiva que despliega el sistema de agricultura tóxica.

\section{Malformaciones y aumento de cáncer}

Después de 18 años de fumigaciones sistemáticas, los equipos de salud de los pueblos fumigados detectan un cambio en el patrón de enfermedades en sus poblaciones: los problemas respiratorios son mucho más frecuentes y vinculados a las aplicaciones de agrovenenos, igual que las dermatitis crónicas. De la misma manera, los pacientes epilépticos convulsionan mucho más frecuentemente en época de fumigación, son más asiduos la depresión y los trastornos inmunitarios y endócrinos. Se registran altas tasas de abortos espontáneos (hasta $23 \%$ de las mujeres en edad reproductiva sufrió al menos un aborto en los últimos cinco años, cuando la tasa normal es de $5 \%$ ) y aumentaron notablemente las consultas por infertilidad en varones y mujeres (REDUAS, 2011). Los rebaños de cabras de los campesinos 


\section{6}

después de 18 años de fumigaciones

sistemáticas, los equipos de salud de los

pueblos fumigados detectan un cambio en el

patrón de enfermedades en sus poblaciones

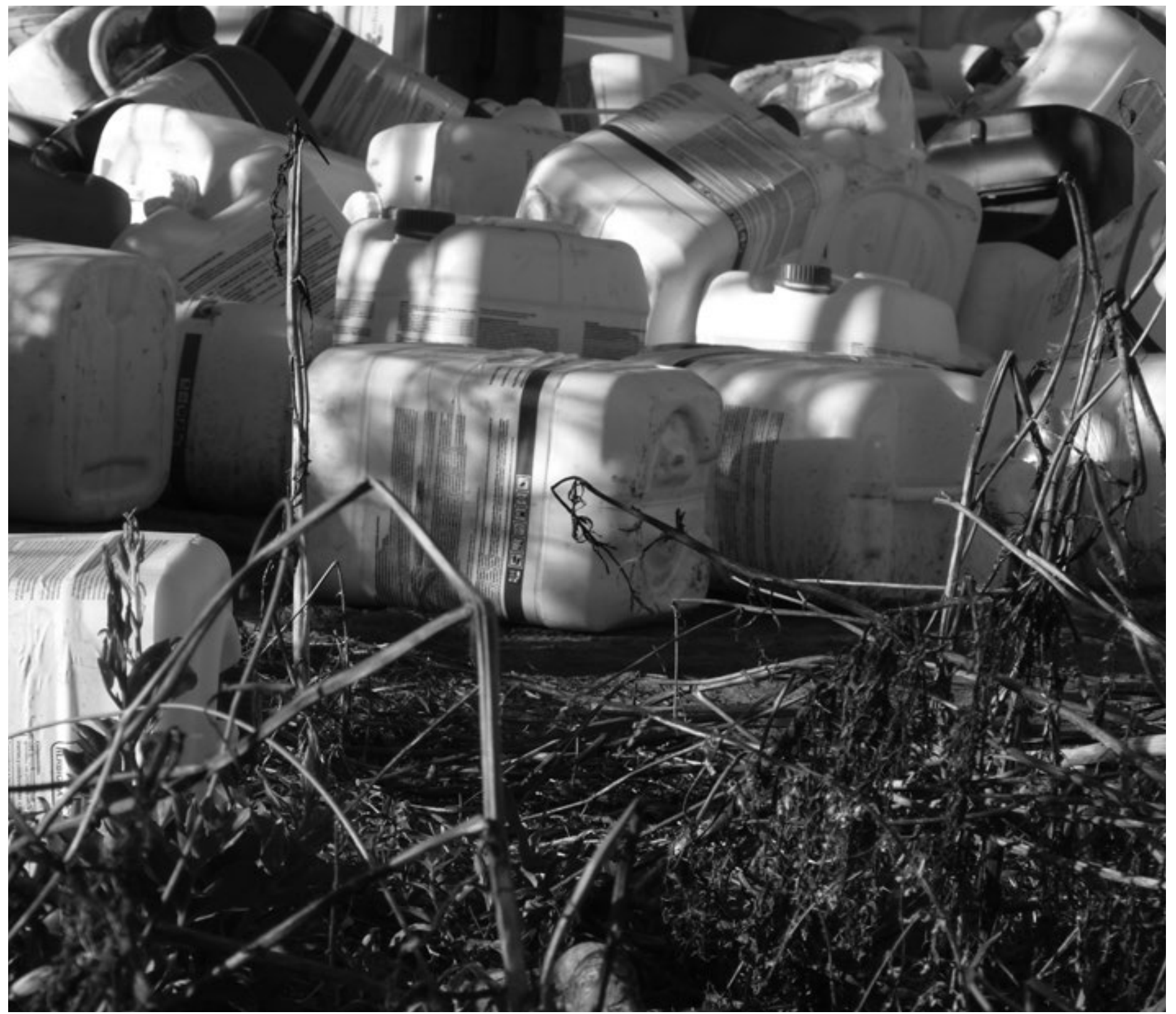


y originarios registran, en algunas zonas, hasta un $100 \%$ de malpariciones (abortos o muertes prematuras por malformación) vinculados a la exposición a pesticidas. Se detecta también un aumento de trastornos tiroideos y de diabetes.

Cada vez nacen más niños con malformaciones en estas zonas, especialmente si los primeros meses del embarazo coinciden con la época de fumigaciones. Síndrome de Down, mielomeningoceles, cardiopatías congénitas, etc., se diagnostican con mayor frecuencia en estas áreas; en algunos pueblos y años llegan a triplicar las tasas normales y se vinculan directamente al aumento de las aplicaciones de agrotóxicos en los alrededores (REDUAS, 2011 y Verzeñassi, 2013).

Los pueblos fumigados también presentan un cambio en sus causas de muerte. Según los datos de los registros civiles a los que hemos podido acceder, encontramos que más del $30 \%$ de las personas que mueren en estos pueblos fallece por cáncer, mientras que en todo el país ese porcentaje es menor al $20 \%$. La mortalidad por cáncer aumentó claramente en estas áreas, lo cual es un fenómeno nuevo detectado por nuestros colegas desde el año 2000 y no verificado antes (REDUAS, 2011; Verzeñassi, 2013 y Ercolano, 2012). Curiosamente, la fecha coincide con la expansión del consumo de glifosato y otros agroquímicos que son masivamente aplicados en la zona.

La ciudad de San Salvador, en Entre Ríos, es recocida como la Capital Nacional del Arroz, pero estas transformaciones agrarias también impactaron en la región, de manera que hoy, en las 70000 hectáreas de la zona, sólo 10000 se mantienen con arroz y las demás producen soja. Este dato sólo tendría interés económico y social si desconociéramos que en los cinco últimos años las mortalidad por cáncer en los vecinos de la región es la más alta detectada por nuestra Red en todo el país. En los años 2011 y 2012 uno de cada dos vecinos murió de cáncer cuando en todo el país sólo uno de cada cinco argentinos muere por causas oncológicas (MU, 2012).

Recientemente, en mayo de 2014, el Ministerio de Salud de la Provincia de Córdoba publicó los datos de su registro de cáncer, que confirman que en las zonas más intensamente agrícolas las muertes a causa de esta enfermedad superan en un $100 \%$ a las de la ciudad capital y en un $70 \%$ al promedio provincial (Fernández, 2014). La agresión química afecta a todas las personas, pero sin duda que los pobres del campo, los peones, sus mujeres y niños, son los que tienen menos posibilidades de protegerse y de recuperar su salud. Además, desde el norte de Córdoba y Santa Fe, la mayor parte de los nuevos emprendimientos de agricultura tóxica es concretada por sociedades anónimas y pooles de siembra que utilizan la vía aérea de fumigación de modo casi generalizado, las dosis de venenos son mucho más altas debido a las condiciones climáticas y biológicas de la región, y las consecuencias las sufren principalmente los pueblos originarios y los campesinos.

\section{Las evidencias científicas}

Las manifestaciones clínicas que los médicos de pueblos fumigados observamos en nuestros pacientes encuentran su causalidad biológica en los resultados de investigaciones científicas en modelos experimentales con diversos plaguicidas, incluyendo glifosato. Así, por caso, investigaciones de científicos de nuestras universidades demuestran de qué manera el glifosato actúa en el desarrollo embrionario produciendo malformaciones (Paganelli, Gnazzo, Acosta, López y Carrasco, 2010), y cómo este veneno genera daño a las moléculas de ADN del núcleo celular, promoviendo líneas celulares mutantes que ocasionarán cáncer si no logran ser eliminadas por el individuo (Mañas, 2009; Simoniello, 2010 y López, 2012).

También, numerosas publicaciones epidemiológicas en todo el mundo demuestran cómo la exposición a agrotóxicos aumenta notablemente las tasas de malformaciones, abortos, cáncer y trastornos hormonales en las personas sometidas a fumigaciones reiteradas (Schreinemachers, 2003; Winchester, 2009; Settimi, 2008 y Clapp, 2008).

Incluso el más alto estándar de análisis crítico de la información científica médica, las Revisiones Sistemáticas de la Medicina Basada en la Evidencia, sostienen la necesidad de disminuir esta exposición por contarse con evidencias suficientemente fuertes y consistentes para reconocer que la exposición a plaguicidas aumenta el riesgo de afectar la salud humana (Sanborn, 2007 y 2012 y Bassil, 2007). Las áreas académicas de la salud no detectaban el problema que se estaba generando como consecuencia de nuestro sistema productivo rural, a pesar de que desde el año 2001 se reiteraban las denuncias y reclamos de vecinos, vecinos tan distantes como los de Los Toldos en Buenos Aires, los de San Jorge en Santa Fe, los de barrios de Ituzaingó en Córdoba o los de la Leonesa en el Chaco. Recién en el año 2010 la Facultad de Medicina de la Universidad Nacional de Córdoba convocó a un encuentro de médicos de pueblos fumigados (REDUAS, 2011) para verificar la existencia del problema y su magnitud. Este encuentro dio origen a la Red Universitaria de Ambiente y Salud / Médicos de Pueblos Fumigados-REDUAS, que interrelaciona equipos de salud que acompañan la lucha de movimientos sociales contra las fumigaciones en contextos donde el poder económico, político y cultural de la soja es agobiante.

A pesar de las denuncias y reclamos, el uso de agrotóxicos en nuestro país no deja de aumentar. En el año 1990, según datos de las propias cámaras empresarias de agrotóxicos, se consumieron 39 millones de litros/kilos equivalentes de agroquímicos (herbicidas, insecticidas y fungicidas); en el año 2013 la misma cámara informó que su negocio casi llegaba a 3000 millones de dólares con 318 millones de litros/kilos vendidos. El glifosato es el agrotóxico más utilizado en Argentina: agrupa el $64 \%$ del total de las ventas y se aplicaron 200 millones de kg/l de glifosato en la última campaña agraria (REDUAS, 2013). 
En estudios de uso realizados por ingenieros agrónomos de la Sociedad Rural Argentina, principal institución sojera del país (Barbarich, 2010), en la zona núcleo (principal área agrícola) se aplicaron casi 10 litros/kilos de agrotóxicos por hectárea por año, lo que equivale para el área de estudio a 31 litros de agrovenenos por cada uno de los pobladores del departamento de General López de Santa Fe. En Argentina estimamos que se aplican 7 litros/kilos de agrotóxicos por cada uno de los 40 millones de habitantes por año, pero en las zonas productivas del agronegocio esas dosis de tóxicos se elevan entre 30 y 45 litros/kilos por persona por año, lo que genera una carga acumulada de agresión química que se refleja irremediablemente en los indicadores más duros de salud, como son las causas de muerte.

\section{Crítica a los postulados} de la biotecnología y su seguridad

El modelo de producción agrícola en la Argentina, conducido por las empresas de biotecnología internacionales, ha generado un aumento del $858 \%$ en la cantidad de agrotóxicos utilizados por año, lo que ocasiona un impresionante impacto ecológico y sanitario en la región. Este aumento del consumo de agrotóxicos no se explica en el incremento de la superficie cultivada: entre 1990 y 2010 el área cultivada por cereales y oleaginosas pasó de 20 millones de hectáreas a 30 millones de hectárea (REDUAS, 2013), es decir que creció un $50 \%$, lo que no puede explicar el aumento de $858 \%$ en el consumo total de agrotóxicos (la utilización en cultivos frutihortícolas y regionales como vid, tabaco y azúcar, explican menos del $15 \%$ del consumo total).
La premisa de que las semillas transgénicas emplean menos agrotóxicos no se puede verificar en la realidad Argentina. En 1996-1997, momento en que comenzó a sembrarse soja transgénica, se aplicaban hasta 3 litros de glifosato por hectárea por año; actualmente se aplican 12 litros de glifosato en esa misma hectárea y por el mismo intervalo de tiempo. Esto demuestra la incapacidad del modelo de agricultura tóxica para enfrentar las respuestas adaptativas de la naturaleza, como el surgimiento de resistencia en las plantas e insectos. La única respuesta refleja es aumentar la dosis de venenos por hectárea (vender más pesticidas a los productores), tanto herbicidas como insecticidas, y agregar agrotóxicos más peligrosos a las mezclas para fumigar y/o agregar apilamientos de "eventos" transgénicos para que las plantas secreten permanentemente varias toxinas insecticidas Bt.

Otro mito de la industria de biotecnología es que se aumenta el rendimiento del cultivo. Sin embargo, cada vez son más numerosos los estudios científicos independientes que demuestran que esto es una falacia. Se reconoce un aumento en la producción de granos (cereales y oleaginosas), pero estas investigaciones muestran que el incremento del rendimiento por hectárea se vincula a técnicas de agricultura tradicional que se fueron incorporando en los últimos 20 años, como el aumento de densidad de plantas por unidad de superficie (menos separación entre plantas en el surco y entre surco y surco), etc. (Quist, 2010 y Gurian-Sherman, 2009). En Argentina, el rendimiento promedio en 1994 fue de 2,2 toneladas por hectárea y en 2010 de 3 toneladas; creció un $30 \%$ el rendimiento promedio de los cultivos (REDUAS, 2013)... pero en ese período consumimos un $858 \%$ más de venenos agrarios: algo no anda bien.

Comparando el consumo de agrotóxicos en millones de kg/por año 

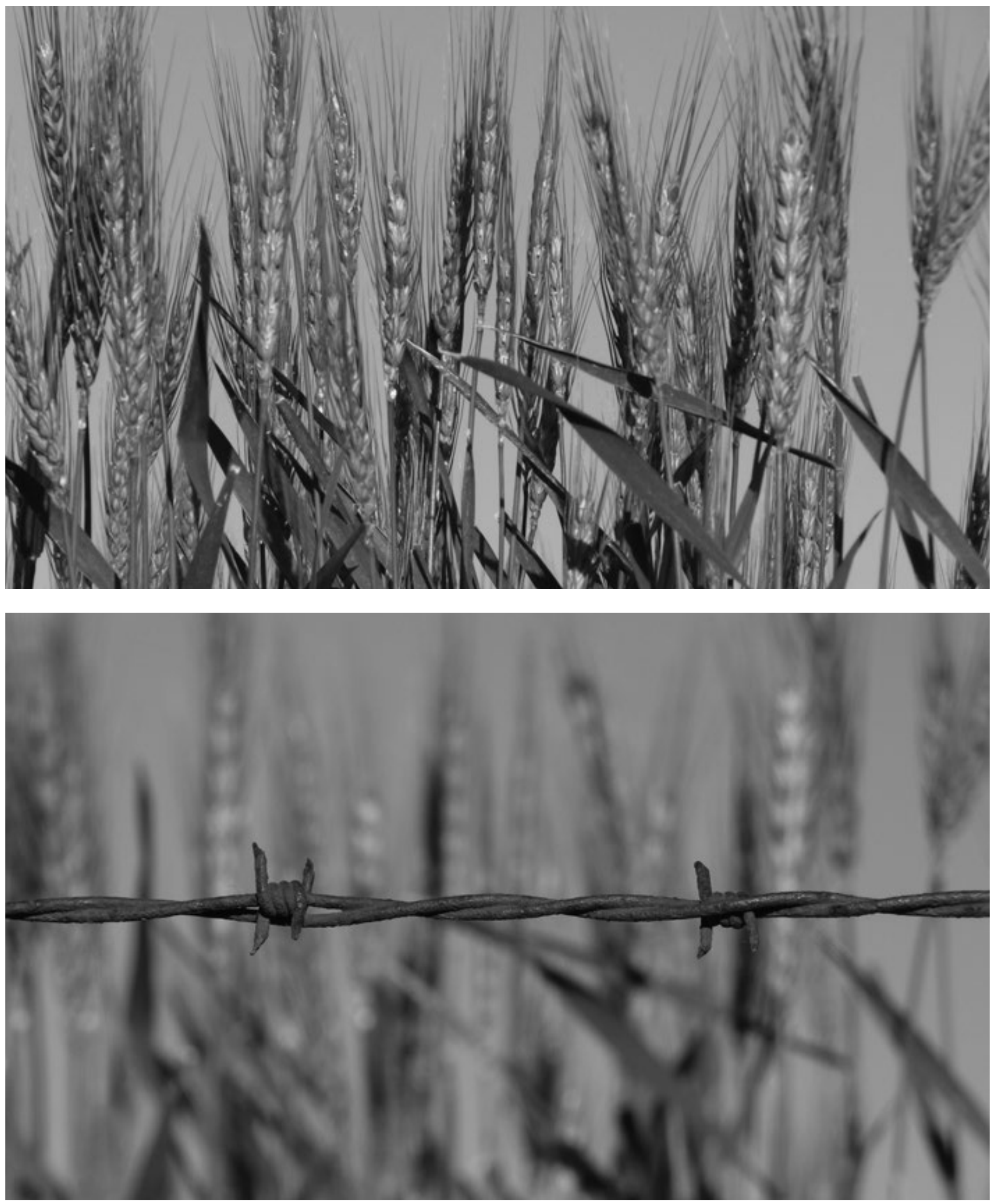
con el aumento de la superficie sembrada en millones de hectáreas y el incremento del rendimiento en toneladas por hectárea, encontramos que el $858 \%$ de crecimiento del mercado de agrotóxicos no se relaciona con un aumento del 50 \% del área sembrada, ni con un $30 \%$ de mayor rendimiento de los cultivos por hectárea.

La ineficacia de la biotecnología utilizada se evidencia en el daño ecológico generado por el desmonte masivo del país; la contaminación creciente que se verifica a lo largo de todos los cursos de aguas superficiales de la región, como el río Suquía (Bonasea, 2012) y el río Paraná en toda su extensión (Marino, 2012); en los niveles de recuperación de glifosato en el agua de lluvia de las zonas sojeras (datos en proceso de publicación), que supera más de 10 veces a las detectadas en EE. UU. (Chang, 2011); en el aumento de las tasa de cáncer, malformaciones congénitas, abortos espontáneos, discapacidad mental, trastornos endócrinos e inmunitarios que padecen las poblaciones rurales expuestas a dosis crecientes de agrotóxicos de año en año y en forma sistemática; y en la carga creciente de residuos de pesticidas en los granos que exporta la Argentina, como ya se verificó en Dinamarca y Holanda, donde desde el año 2015 se priorizará la compra de soja y maíz orgánico para alimentar a su ganado (GM Watch, 2012 y Fastrup, 2011).

Los residuos crecientes de pesticidas en alimentos elaborados con granos impregnados por estos agrovenenos son una preocupación creciente en Europa, y su peligrosidad ha quedado en evidencia sobre todo después de las investigaciones del francés Eric Seralini. Recientemente, se detectó en estudiantes de la Universidad de Berlín y en europeos de 18 países distintos la presencia de glifosato en la orina, menos elevada en los adeptos a la alimentación orgánica; en ganado vacuno y en conejos se verificaron resultados similares: mayor cantidad de glifosato en orina y en tejidos en los animales alimentados con forrajes transgénicos (Kruger, 2014). Ante los problemas de resistencia en malezas e insectos, la respuesta de la industria biotecnológica (Monsanto, Bayer, Dow, Dupont, etc.) es más de lo mismo. Se promueven nuevas semillas transgénicas con resistencia al glifosato, al glufosinato y al 2.4D (y próximamente al paraquad), y en pocos años los resultados serán similares con respecto a los niveles de residuos de pesticidas en los granos: cada vez más elevados.

También se promueven semillas resistentes a varios herbicidas y a la vez productoras de toxinas Bt, como Cry1A.105, Cry2Ab, Cry3Bb, que, por ahora, confieren protección contra lepidópteros y coleópteros pero que perjudican a una enorme cantidad de insectos benéficos y útiles para sostener el equilibrio ecológico. No existen certezas de la inocuidad de estas toxinas en humanos. Por 100000 años, nuestra especie tuvo contacto con ínfimas cantidades de estas toxinas, pero ahora, por la magia de la biotecnología, nos exponemos a una enorme cantidad de estas proteínas que ya fueron recuperadas en la leche materna humana, en sangre humana y en sangre del cordón umbilical humano, y que además sabemos que generan riesgo inmunitario y alérgico para las personas (Aris, 2011), y probablemente sus consecuencias tóxicas sean mucho mayores cuando empecemos a ver los resultados de esta novel exposición dentro de unos pocos años.

La naturaleza no reinventa la rueda. Cuando encuentra una forma de hacer las cosas, la repite a lo largo de toda la evolución. Atacar indiscriminadamente con tóxicos químicos una maleza, un insecto o un roedor, equivale a atacarnos a nosotros mismos.

Hoy conocemos que el $40 \%$ de los genes del genoma humano lo compartimos con las plantas y regula nuestras actividades celulares de manera similar que en los vegetales. También sabemos que el $60 \%$ de los genes de los insectos está en nuestro código genético, o sea que compartimos con insectos y plantas muchos de los mecanismos íntimos del metabolismo celular. Podremos atacar masivamente con químicos a esos mecanismos, trabarlos, distorsionarlos para generar la muerte de plantas o insectos, pero no podemos ignorar que, si esos tóxicos alcanzan a las personas, ya sea por exposición ocupacional, por exposición habitacional o por ingerir agua o alimentos contaminados con sus residuos, inevitablemente tendrán efectos perjudiciales sobre aquéllas, no podemos suponer que son inocuos.

Desde hace años conocemos, por la realización de estudios radioisotópicos, que el flujo de la materia a través de nuestro cuerpo es muy veloz. Sabemos que las células de nuestra piel son nuevas en menos de cinco semanas, que las células de la mucosa gástrica viven menos de un día, que nuestro esqueleto está renovado en un año. Las células de nuestro cerebro, las neuronas, no se reproducen pero su estructura molecular interna es totalmente renovada varias veces al año. El flujo de los átomos de oxígeno, carbono, hidrógeno y nitrógeno a través de nuestro cuerpo es rapidísimo; sólo los átomos de hierro, magnesio y cobre más pesados demoran este recambio y el $98 \%$ de los átomos de tejidos y células es totalmente sustituido en un año. Este flujo continuo de la materia entre nuestro cuerpo y el ambiente es continuo; si los niveles de contaminación ambiental crecen, la salud colectiva será cada vez más difícil. 


\section{Bibliografía}

Aris, A.; Leblanc, S. (2011). "Maternal and fetal exposure to pesticides associated to genetically modified foods in Eastern Townships of Quebec, Canada". Reprod Toxicol. May 31(4):528-533. doi: 10.1016/j.reprotox.2011.02.004. Epub 2011. Feb. 18.

Barbarich, C. (28 de junio de 2010). "El departamento G. López lidera el consumo de agroquímicos provincial”. La Capital. Recuperado en: http://www.lacapital. com.ar/la-region/El-departamento-G.-Loacutepez-lidera-el-consumo-de-agroquiacutemicos-provincial-20100628-0016.html

Bassil, K. L.; Vakil, C.; Sanborn, M.; Cole, D. C.; Kaur, J. S.; Kerr, K. J. (2007). "Cancer health effects of pesticides: systematic review". Can Fam Physician, Oct. 53(10):1704-1711.

Bonansea, R. I.; Amé, M. V.; Wunderlin, D. A. (2012). "Determination of priority pesticides in water samples combining SPE and SPME coupled to GC-MS. A case study: Suquía River basin (Argentina)". Chemosphere. 2013 Feb., 90(6):18601869. doi: $10.1016 / \mathrm{j}$.

Chang, F. C.; Simcik, M. F.; Capel, P. D. (2011). "Occurrence and fate of the herbicide glyphosate and its degradate aminomethylphosphonic acid in the atmosphere". Environ Toxicol Chem. 2011 Mar. 30(3):548-355. doi: 10.1002/etc.431. Epub 2011 Jan. 19.

Clapp R. W.; Jacobs M. M; Loechler E. L. (2008). "Environmental and occupational causes of cancer: new evidence 2005-2007". Environ Health. Jan.-Mar. 23(1):1-37. Ercolano, M. (19 de mayo de 2012). "En los pueblos fumigados, el 30 \% de las muertes son por cáncer". Tiempo Argentino. Recuperado en: http://tiempo. infonews.com/2012/05/19/sociedad-76024-en-los-pueblos-fumigados-el-30-delas-muertes-son-por-cancer.php

Fastrup, N. (1 de noviembre de 2011). "Politiken Kræft får ikke landbruget til at droppe sprøjtet soja". Danmark. Recuperado en: http://politiken.dk/indland/ ECE1436886/kraeft-faar-ikke-landbruget-til-at-droppe-sproejtet-soja/

Fernández, M. (29 de mayo de 2014). "Cáncer en Córdoba: en el este provincial, la mortalidad más alta". La Voz del Interior. Recuperado en: http://www.lavoz.com. ar/ciudadanos/cancer-en-el-este-provincial-la-mortalidad-mas-alta GM Watch (27 de abril de 2012). GM soy linked to health damage in pigs - a Danish Dossier. Disponible en: http://www.gmwatch.org/files/GM-Soy-linked-tohealth-damage-in\%20pigs-a-Danish-Dossier.pdf

Gurian-Sherman, D. (2009). "Failure to Yield: Evaluating the Performance of Genetically Engineered Crops". Union of Concerned Scientists. USA. Mar. Recuperado en: http://www.reduas.fcm.unc.edu.ar/wp-content/uploads/downloads/2011/07/ failure-to-yield-brochure-UCS.pdf

Kerr, K. J. y otros (2007). "Non-cancer health effects of pesticides: systematic review and implications for family doctors". Can Fam Physician, Oct. 53(10):1712-1720. Krüger, M.; Schledorn, P.; Schrödl, W.; Hoppe, H. W.; Lutz, W.; Shehata, A. A. (2014). "Detection of Glyphosate Residues in Animals and Humans". J Environ Anal Toxicol, 4:2. doi: 10.4172/2161-0525.100021

Lapolla, A. (2008). "Reportaje". Entrelíneas de la Política Económica, 13, pp. 20-26. Centro de Investigación en Economía Política y Comunicación. Universidad Nacional de La Plata. Recuperado en: http://sedici.unlp.edu.ar/bitstream/handle/10915/15345/Documento_completo.pdf?sequence=1
López, S. L. y otros (2012). "Pesticides Used in South American GMO-Based Agriculture: A Review of Their Effects on Humans and Animal Models". En: Advances in Molecular Toxicology 6:41-75. Amsterdam: The Netherlands.

Mañas, F. y otros (2009). "Genotoxicity of glyphosate assessed by the comet assay and cytogenetic tests". En: Environ Toxicol Pharmacol (1):37-41. doi: 10.1016/j.etap.2009.02.001. Epub 2009 Feb. 11.

Marino, D. J. y otros (2012). Monitoreo de plaguicidas en principales afluentes de la cuenca Paraguay-Paraná. IV Congreso SETAC Argentina. Society of Environmental Toxicology and Chemestry. Recuperado en: http://media.lavaca.org/pdf/ mu/mu75.pdf

Paganelli, A.; Gnazzo, V.; Acosta, H.; López, S. L.; Carrasco, A. E. (2010). "Glyphosate-based herbicides produce teratogenic effects on vertebrates by impairing retinoic acid signalling". En: Chem Res Toxicol 23(10):1586-1595. DOI: 10.1021/ tx1001749. Epub 2010 Aug. 9.

Quist, D. (2011). Evaluando la contribución de los rasgos genéticamente modificados al rendimiento de los cultivos. GenØk - Centro de Bioseguridad, Noruega. Recuperado en: http://www.reduas.fcm.unc.edu.ar/evaluando-la-contribucion-de-los-rasgos-geneticamente-modificados-al-rendimiento-de-los-cultivos-\%C2\%BFadopcion-o-alternativas-para-la-politica-agricola/ REDUAS (2011). "Report from the First National Meeting of Physicians in the Crop-Sprayed Towns". En: University Network for Environment and Health - Physicians of Crop-Sprayed Towns. Recuperado en: http://www.organicconsumers. org/documents/INGLES-Report-from-the-1st-National-Meeting-Of-Physicians-InThe-Crop-Sprayed-Towns.pdf

REDUAS (2013). "The use of toxic agrochemicals in Argentina is continuously increasing". En: University Network for Environment and Health - Physicians of Crop-Sprayed Towns. Recuperado en: http://www.reduas.fcm.unc.edu.ar/ the-use-of-toxic-agrochemicals-in-argentina-is-continuously-increasing/ Sanborn, M.; Bassil, K.; Vakil, C.; Kerr K. (2012). Systematic Review of Pesticide Health Effects. Department of Family Medicine, McMaster University. Ontario College of Family Physicians. Recuperado en: http://ocfp.on.ca/docs/pesticides-paper/2012-systematic-review-of-pesticide.pdf?sfvrsn=6

Schreinemachers, D. M. (2003). "Birth malformations and other adverse perinatal outcomes in four U.S. Wheat-producing states". En: Environ Health Perspect, Jul. 111(9):1259-1264.

Settimi, L.; Spinelli, A.; Lauria, L.; Miceli, G.; Pupp, N.; Angotzi, G. (2008). "Spontaneous abortion and maternal work in greenhouses". En: Am. J Ind. Med. 51(4):290-295.

Simoniello, M. F.; Kleinsorge, E. C.; Scagnetti, J. A.; Mastandrea, C.; Grigolato, R. A.; Paonessa, A. M.; Carballo, M. A. (2010). "Biomarkers of cellular reaction to pesticide exposure in a rural population". Biomarkers, Feb. 15(1):52-60. doi: 10.3109/13547500903276378.

Verzeñassi, D. (5 de agosto de 2013). "Argentina, Santa Fe: Estudio vincula fumigaciones con enfermedades en los pueblos". Argenpress. Disponible en: http:// www.argenpress.info/2013/08/argentina-santa-fe-estudio-vincula.html Winchester, P. D.; Huskins, J.; Ying, J. (2009). "Agrichemicals in surface water and birth defects in the United States". Acta Paediatr, Apr. 98(4):664-669. 